\title{
Grounding Type and Application for Transmission Line Pole and Tower
}

\author{
Xiaoyan Huang \\ Sichuan College of Architectural Technology, Deyang, Sichuan, 618000,China \\ email: hxy681018@163.com
}

Keywords: Soil resistivity;Reducing agent;Grounding device; Grounding module.

\begin{abstract}
The line project of pole and tower grounding device in Sichuan Province are analyzed in this paper,It points out some problems transmission line tower grounding existing at present.Several kinds of grounding types for transmission line pole and tower are discussed in detail.A closed loop grounding device is used in paddy field and residential area with the actual terrain,radiation type grounding device add reducing resistance agent or the grounding module in the high soil resistivity area, to better realize the safe and reliable operation of the power supply line.
\end{abstract}

\section{Introduction}

The main effect of grounding device for overhead transmission line tower is to lightning current into the earth, and to reduce the power outage caused by lightning strike and accidents.Transmission line tower grounding device exist some hidden trouble for safety, especially in personnel activity frequent region have larger influence on the safety of the person.

The grounding device is divided into vertical and horizontal closed loop grounding device and a radial grounding device.Selection of grounding device mainly depends on soil resistivity 、 topography of the tower area etc.The correct choice of grounding device is effective measures to ensure personal safety.

\section{Analysis of existing problems of transmission line tower grounding at present}

The main reasons for the high ground resistance for transmission line tower at present has the following 3 points : (1)There is no measure of pertinence resistance reduction the soil resistivity seriously exceed the standard in rock area,according to the survey, the soil resistivity of the southern part of the region are as high as $2000 \sim 5000 \Omega \cdot \mathrm{m}$ [4], Once the lightning,Lightning flow channel is not smooth, resulting in frequent lightning accident. (2) The earth body is not deep enough.Especially in mountainous area and rock area, because of the difficulty of excavation, the earth body is shallow, and no fine soil backfill is used.(3)Radiation grounding device of the length is not in accordance with standard construction.

\section{Method for reducing the transmission line tower grounding resistance}

\subsection{Horizontal epitaxial grounding body}

When the tower location allows you to set the level of radiation grounding, as far as possible the level of radiation grounding body.Because of the low level of the construction cost, good dispersion effect,not only can reduce the power frequency grounding resistance, but also can effectively reduce the impact grounding resistance[3],according to the different soil resistivity can determine the length of the radiation levels, as shown in Table 1[6].

Extension grounding to security check, taking into account the step voltage problem[5]. 
Table 1 the maximum length of each radial grounding in tower grounding

\begin{tabular}{|c|c|c|c|c|}
\hline soil resistivity $(\Omega . \mathrm{m})$ & $\rho \leq 500$ & $500<\rho \leq 1000$ & $1000<\rho \leq 2000$ & $2000<\rho \leq 5000$ \\
\hline The maximum length $(\mathrm{m})$ & 40 & 60 & 80 & 100 \\
\hline
\end{tabular}

\subsection{Deep grounding electrode}

Deep grounding electrode with grounding parameter stability, not easy to be destroyed, save land etc.Geological conditions for the application of deep well grounding method is: the soil resistivity of the upper and lower layer is little, and the ground can not be extended. limited by the terrain,or lower soil resistivity is much lower than the upper soil resistivity.

It should pay attention to the following points in the choice of embedding location: the groundwater level is higher;the grounding body can be inserted into the ore body if the metal ore near the tower, to extend or expand geometrical dimensions of earth body use of ore bodies; insert the grounding body the use of rock cracks and poured into reducing agent ;laying underwater grounding device If there is a water tower near can receive very good results.

\subsection{Using the reducing resistance agent}

The best use of the reducing resistance agent is a medium and small grounding device with high soil resistivity.But there are problem of reducing resistance effect, corrosion to grounding body, Stability and long-term performance[1], of the resistance reducing agent itself etc in the use of the resistance reducing agent,so it is very important to choose and use the reducing resistance agent correctly, and the choice of reducing agent should be considered in the following several aspects: the resistivity of the reducing resistance agent is small;and has good stability and long term performance;no corrosion to grounding body, etc.

\section{Form and engineering examples of grounding device}

According to the "grounding design specification for AC electrical installations" GB/T50065-2011,grounding device for overhead line tower can be used the following types: artificial grounding device should be added for $100 \Omega \cdot \mathrm{m}<\rho \leq 300 \Omega \cdot \mathrm{m}$ region ; The grounding device can be used for horizontal laying for $300 \Omega \cdot \mathrm{m}<\rho \leq 2000 \Omega \cdot \mathrm{m}$ region;the radial electrode can be used 6-8 root total length of not more than $500 \mathrm{~m}$ for $\rho>2000 \Omega \cdot \mathrm{m}$. The grounding device should be around the tower foundation laying into a closed ring in the residential area and paddy field[6].

\subsection{The closed - shaped grounding device}

The closed - shaped grounding device is one of the main grounding modes in the transmission line in the Sichuan plain,has closed loop and square two ways,mainly used in $\rho \leq 500 \Omega \cdot \mathrm{m}$ in paddy field and dry land.In the dry land and flat hilly area, the type of the combination of the shallow buried earth ring and the deep buried earth ring[2],closed square earth body is shown in Fig. 1 (a) [2].Closed loop grounding body for paddy fields and residential areas, as shown in Fig. 1 (b) [3].

Such as $110 \mathrm{kV}$ Line Project for the original Jiuguang Line,Longdong Line in Mianzhu City, Sichuan Province,this project is located in the eastern part of Mianzhu two loop and the plains of the land, the main use of the radial grounding device for horizontal laying in the transmission line,it is achieved that the tower of power frequency grounding resistance is reduced to below $15 \Omega$ after the installation grounding device. 


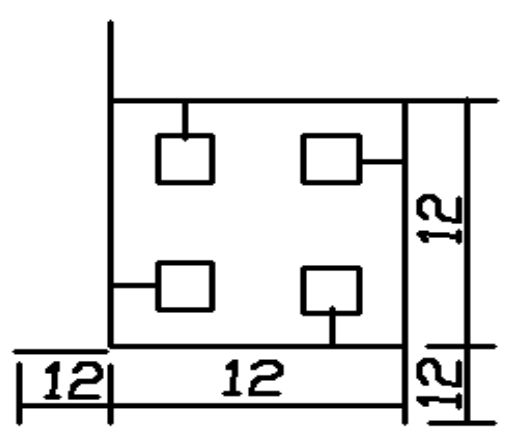

(a) Closed square grounded body

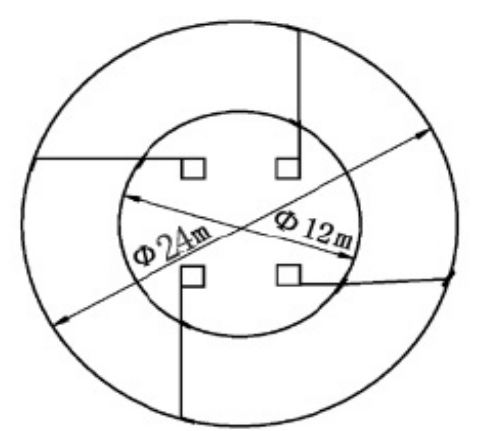

(b) Closed loop grounding body

Fig. 1 Schematic diagram of closed form of grounding body

\subsection{Radiation type grounding device added reducing resistance agent}

In the engineering of high soil resistivity in Sichuan area,the type is often used that radiation type grounding device added reducing resistance agent.Such as disaster recovery $10 \mathrm{kV}$ Line Project in Sichuan Mianzhu Jinhua Town, this line begins in the Ganhekou of Red and White Town in Shifang City terminate in Chengqiangyan Phosphate rock,terrain is complex, it is used the way that radiation type grounding device added reducing resistance agent in Hero rock mining area,as shown in Fig.2[3].Grounding resistance mainly depends on the soil resistivity of the upper layer.,by lowering the upper soil resistivity and increasing the soil thickness,to reduce the grounding resistance.

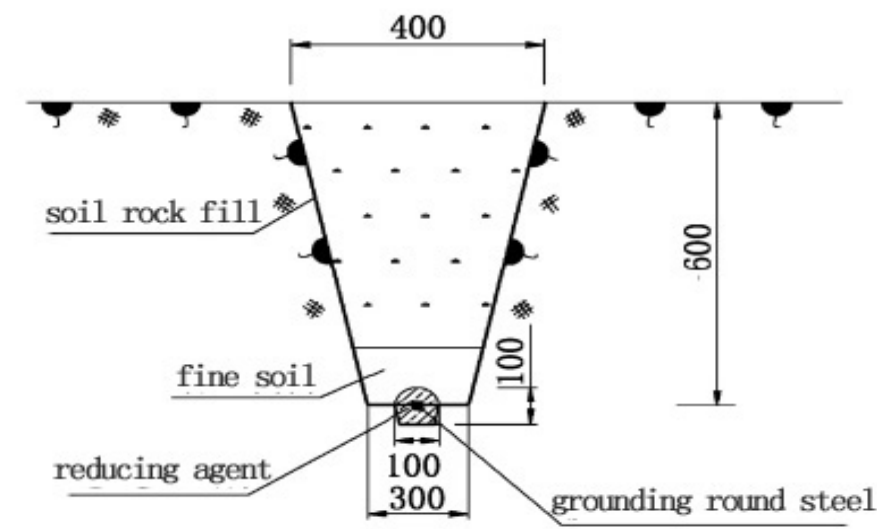

Fig.2 The section drawing of grounding trench (added reducing resistance agent)

\subsection{Adding grounding module for radial grounding device}

In high soil resistivity region based on rock,when traditional method is difficult to meet the requirements of tower grounding resistance,appropriate use of grounding

module, can effectively reduce the grounding floor area and can significantly reduce the tower impulse grounding resistance.The main raw material of the grounding module is Shi Mofen,Because graphite sensitivity to environmental is very low, almost no external factors are affected, so grounding resistance of grounding module can be maintained for a long time,this is a traditional grounding material can not match.Fig.3 is a schematic diagram of grounding module[3].

The number and the length of rays, and the number of modules can be selected according to different soil resistivity.Such as disaster recovery $10 \mathrm{kV}$ Line Project in Sichuan Mianzhu Jinhua Town, the rock is the main in Chengqiangyan Phosphate rock area,the tower is located in the mountains, at an altitude of $1600 \mathrm{~m}$.Because of the limited surface area and high resistivity of soil, so it is used the way of adding grounding module for radial grounding device.Fig.4 is actual diagram of grounding module as $\rho<2000$,Fig. 5 are actual diagram of grounding module as $\rho>2000$

Earth module can be vertical or horizontal embedded, The grounding electrode is connected in parallel, each electrode spacing is not less than 5 meters, After the burial, the use of fine soil backfill and water compaction.Grounding electrode installation,side view as shown in Fig. 6 (a), top view as shown in Fig. 6 (b) [3]. 


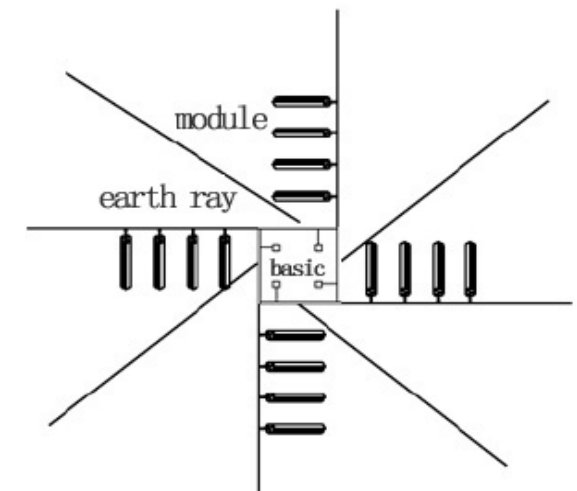

Fig.3. Schematic diagram of module

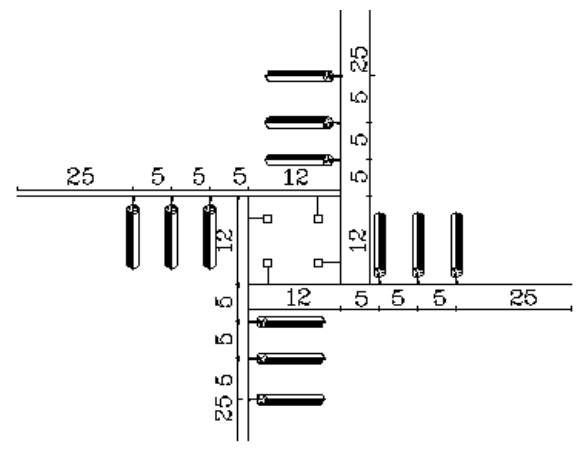

Fig.4 $\rho<2000$, actual diagram of grounding grounding module
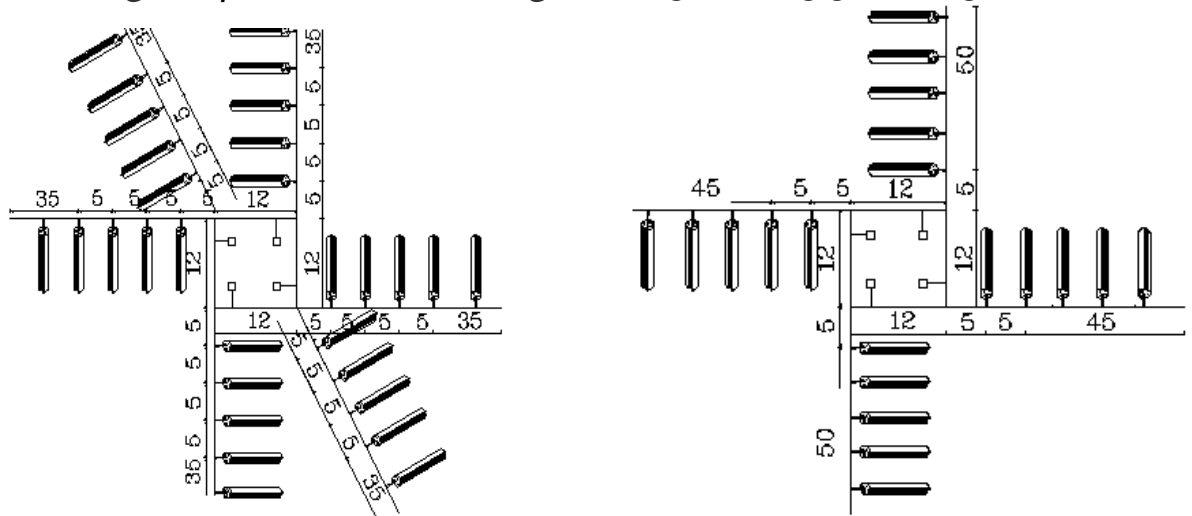

Fig. $5 \rho>2000$, actual diagram of grounding module (the maximum allowable power frequency resistance is $30 . \Omega$ )

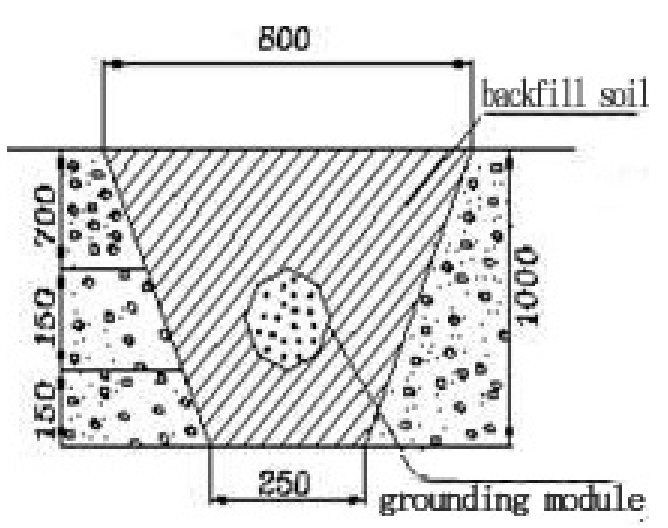

(a) side view

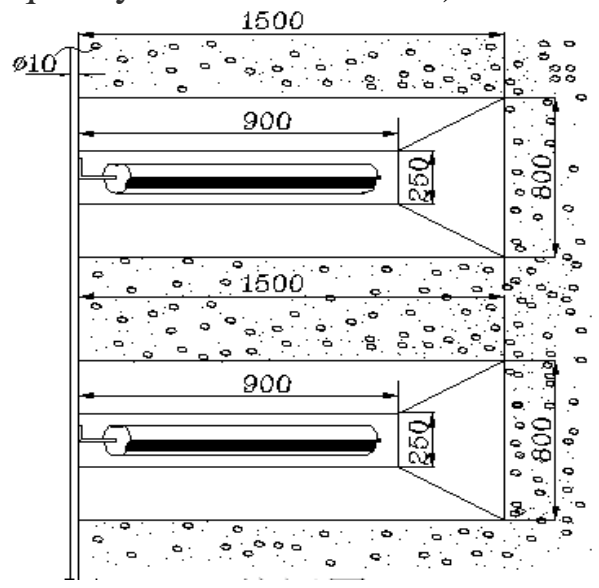

(b) top view

Fig.6 Grounding electrode installation diagram

\subsection{Vertical grounding device}

The vertical grounding device is mainly used in the transmission line of the steel pipe and the 
part of the housing intensive residential area [3].The positive diagram of the steel tube pole is shown in Fig. 7 .for example,Gongxing Industrial Park 110kV new project for four return line same pole in Ma Liu Station - Hua Feng company Deyang, Mianzhu City, Sichuan Province,New 110kV overhead line from $110 \mathrm{kV}$ Ma Liu Station , 35kV cable outlet bypass housing intensive of eighteen groups in Xiangliu village, $110 \mathrm{kV}$ line single back across the thirteen road access to Hua Feng company.Path length is $4.18 \mathrm{~km}$,double circuit line all adopt steel tube pole.The advantage of vertical grounding device is that the ground floor area is small.,so all tower of the project adopt vertical grounding device,tower type is 1GGD2-SZG2.The schematic diagram of the vertical grounding device is shown in Fig. 8[3].

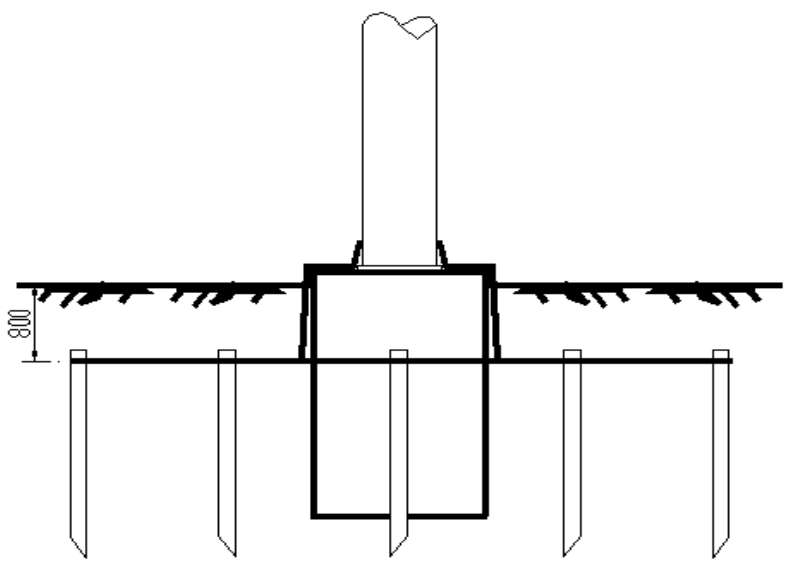

Fig.7 The positive diagram of the steel tube pole

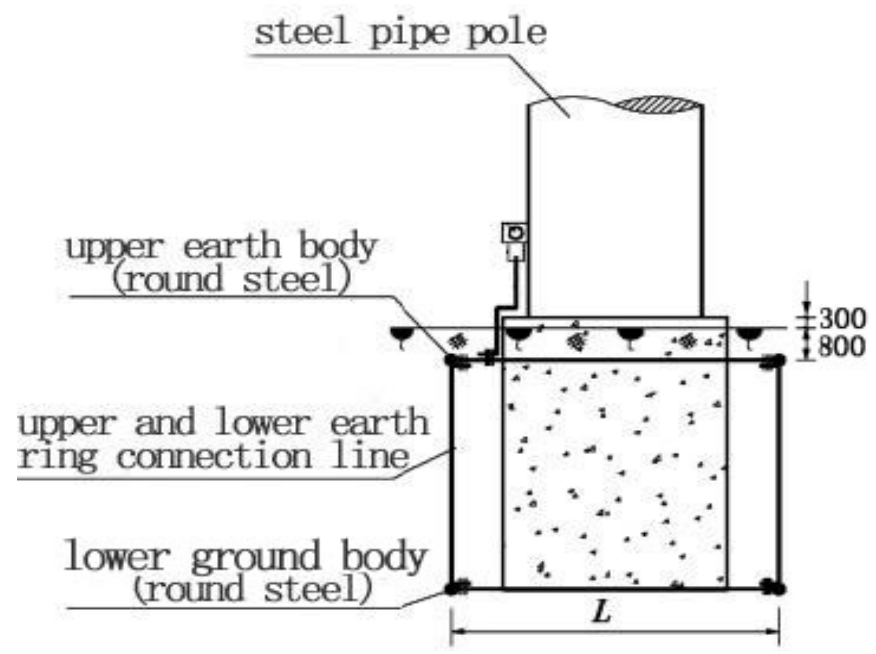

Fig.8 Schematic diagram of the vertical grounding device

\section{Conclusion}

The main purpose of grounding device of overhead transmission line pole and tower is to prevent lightning strikes, the correct choice of grounding device is effective measures to ensure personal safety.Closed - shaped grounding device can be used in the field of paddy field and some residential area.Radiation type grounding device add reducing resistance agent or the grounding module in the mountain area. Doing specific technical and economic analysis for specific engineering, make realistic design, to eliminate the safety hazards to ensure personal safety.

\section{Reference}

[1] Feng ZHOU. Study on the impact assessment and protective measures of grounding device for personal safety transmission line tower [D]. Changsha University of science and technology, 2012,04:21-22 
[2] Jiaquan HU. Design and application of grounding device for Jiangxi 220kV transmission line tower [D]. Nanchang University, 2010,12: 15-19,

[3] Chen Xiang, Analysis of grounding device for Guangxi $110 \mathrm{kV}$ transmission line tower [J], Red River, 2012(6):90-92.

[4] Zhihua LIAO. Optimization measures of grounding system of the grounding system for power transmission tower[D]. Changsha University of Science and Technology, 2013,04:12-13.

[5] Jinglu LI ,Chao LI et al. Application of the reduced resistance modification for epitaxial grounding in substation [J]. Journal of electric power science and technology,2008,23(1):91-92.

[6] Specification for grounding design of AC electrical installations GB/T50065-2011[S].

Beijing: China Planning Press,2012. 